\title{
Interferon gamma induction of gastric mucous neck cell hypertrophy
}

\author{
Weiqun Kang ${ }^{1}$, Sivaprakash Rathinavelu ${ }^{1}$, Linda C Samuelson ${ }^{2}$ and Juanita L Merchant ${ }^{1,2}$ \\ ${ }^{1}$ Department of Internal Medicine, University of Michigan, Ann Arbor, MI, USA and ${ }^{2}$ Department of \\ Molecular and Integrative Physiology, University of Michigan, Ann Arbor, MI, USA
}

\begin{abstract}
Chronic inflammation of the gastric epithelium is believed to induce mucosal changes that can eventually develop into gastric cancer. In gastrin-deficient $\left(G_{-}-{ }_{-}\right)$mice exhibiting chronic inflammation in the hypochlorhydric stomach, we documented a prominent fundic mucous cell lineage sharing morphological similarity with preneoplastic changes reported in Helicobacter-infected mice. To study the identity and origin of this cell lineage, we screened for different gastric mucosal cell markers. The clusters of large, foamy cells stained for trefoil factor 2 (TFF2/SP), MUC6 and the lectin Griffonia Simplicifolia II (GSII), but not for the intestine-specific transcription factor $\mathrm{Cdx2}$, suggested that they arise from gastric mucous neck cells. Ki67labeled GSII-positive neck cells in Helicobacter felis-infected, but not G-I- stomachs, suggested that mucous neck cell proliferation accounted for expansion of this compartment in the $H$. felis model of gastritis, but not the G-I- model. Using RNase protection assays and quantitative PCR, we found that interferon gamma (IFN $\gamma$ ) was the most abundant proinflammatory cytokine in the $\mathrm{G}-I$ - stomach. We also found that this Th1 cytokine can increase the abundance of mucous neck cells, since its infusion into mice recapitulated the appearance of these cells as observed in both $\mathrm{G}-I-$ and $H$. felis-infected mice. Using the human gastric cell line $\mathrm{NCl}-\mathrm{N} 87$, we showed that IFN $\gamma$ induces the secretion of mucus and expression of MUC6, TFF2 and pepsinogen II, but not of pepsinogen I and intrinsic factor. In conclusion, our results demonstrate that inflammation, specifically the proinflammatory cytokine IFN $\gamma$, induced expansion of the fundic mucous neck cell compartment, which likely represents both increased mucus production and cell number.

Laboratory Investigation (2005) 85, 702-715, advance online publication, 14 March 2005; doi:10.1038/labinvest.3700260
\end{abstract}

Keywords: inflammation; griffonia simplicifolia II (GSII); trefoil factor 2 (TFF2); Cdx2; Helicobacter felis; gastric cancer

Gastric adenocarcinoma is the second leading cause of cancer-death in the world., ${ }^{1,2}$ Helicobacter pylori is believed to increase significantly the risk of developing both intestinal and diffuse histological variants of gastric adenocarcinoma. ${ }^{3}$ According to widely accepted dogma, the sequence of events in the development of intestinal-type cancer due to $H$. pylori includes a progression from chronic gastritis, to atrophic gastritis, intestinal metaplasia, and finally to dysplasia and adenocarcinoma. ${ }^{1,4}$ In addition to the direct effects from bacterial virulence factors, this paradigm points to chronic inflammation as the initial step and the critical promoting factor in gastric transformation from $H$. pylori infection. ${ }^{4}$ However to date, the molecular mechan-

Correspondence: Dr JL Merchant, MD, PhD, 1150 West Medical Center Drive, MSRB I, Rm. 3510, Ann Arbor, MI 48109-0650, USA.

E-mail: merchanj@umich.edu

Received 4 January 2005; revised 7 January 2005; accepted 11 January 2005; published online 14 March 2005 isms underlying this chain of events remains largely unknown. ${ }^{2}$ To begin to define these mechanisms, it is important to analyze the cellular changes in the gastric mucosa that are consistently induced by gastric inflammation and may subsequently evolve into dysplasia and cancer.

Our previous studies have shown that gastrindeficient (G-/-) mice are hypochlorhydric, and develop severe gastric inflammation from nonHelicobacter bacterial colonization by 4 months of age. ${ }^{5}$ A majority of these mice $(60 \%)$ develop intestinal gastric adenocarcinoma by 12 months of age. ${ }^{6}$ Emergence of a prominent mucous cell lineage (the so-called 'mucous cell metaplasia') was found to be one of the earliest histological changes in the fundic mucosa of these mice. ${ }^{5}$ Mucosal changes bearing similar features have also been reported in a variety of pathological processes in human and mouse, which include $H$. pylori infection; ${ }^{7-9}$ loss of parietal cells upon chemical administration; ${ }^{10}$ treatment with a carcinogen, ${ }^{11}$ mutation of the Kcnq1 gene encoding a potassium channel, ${ }^{12}$ 
and constitutively active STAT3. ${ }^{13}$ This type of mucosal change may therefore represent a common, and possibly reversible ${ }^{10}$ response of the stomach, to mucosal injury and tissue inflammation triggered by various stimuli. Apart from G-/- mice, studies on other animal models and human subjects further indicate a strong association between the early appearance of this mucous cell lineage and gastric transformation. ${ }^{7,9,14}$

The appearance of these aberrant fundic mucous cells has been described as metaplastic, primarily due to their Brunner's gland-like morphology featuring clusters of large clear cells, which are not obvious in normal gastric mucosa. ${ }^{7,9}$ These cells have also been shown to be positive for spasmolytic polypeptide (SP/TFF2), hence the name spasmolytic polypeptide-expressing metaplasia (SPEM). ${ }^{7}$ In general, 'metaplasia' is a descriptive, histopathological term, which is not well defined at the molecular level. The pathological definition of metaplasia is the 'conversion of one differentiated cell type to another differentiated cell type in response to tissue injury'. ${ }^{15}$ Despite the designation of SPEM to describe the emergence of mucous cells in response to gastric injury, there remains a lack of convincing evidence to show either the origin of these cells or what type of cell they become. This gap in our knowledge hinders our understanding of how this cell lineage might link gastric inflammation to transformation.

G-/ - mice provide us with the opportunity to further characterize this mucous cell lineage, in the context of chronic gastritis that progresses to distal gastric cancer. In the present study, we focused on early mucosal changes that occur within these mice by 4 months of age and coincide with the presence of chronic gastritis. Our aims were three-fold: first, to identify markers of the mucous cells that emerge in the fundus of the $\mathrm{G}-/$ - mice; second, to identify the major proinflammatory cytokine(s) generated in the gastric mucosa of the $\mathrm{G}-/-$ mice, and to determine whether it can induce the appearance of this cell type in vivo; third, to test directly whether the cytokine induces mucous cell gene expression in vitro.

\section{Materials and methods}

\section{Animals}

G-/- and strain-matched wild-type (WT) control mice were maintained on a mixed $129 / \mathrm{Sv}-\mathrm{C} 57 \mathrm{BL} / 6$ background. ${ }^{16}$ The animals were housed in microisolator, solid-bottomed polycarbonate cages in nonbarrier mouse rooms (conventional housing). Food and water were not autoclaved. The study was performed with the approval of the University of Michigan Animal Care and Use Committee, which maintains an American Association for the Assessment and Accreditation of Laboratory Animal Care facility.

\section{Interferon Gamma Infusion}

Wild-type C57BL/6 mice were anesthetized at 2 months of age with xylazine $(20 \mathrm{mg} / \mathrm{ml})$ and ketamine $(100 \mathrm{mg} / \mathrm{ml})$ to insert the Alzet microosmotic pump (Model 1002, Durect Corporation, Cupertino, CA, USA) into the peritoneal cavity. The pump delivered $250 \mathrm{U} / \mathrm{kg}$ ( $15 \mathrm{U}$ per mouse per day) of recombinant mouse interferon gamma (IFN $\gamma)(\mathrm{R} \& \mathrm{D}$ System) or PBS into the peritoneal cavity for 14 days, before the mice were killed for analysis. Three separate experiments were performed using four mice per experiment.

\section{Helicobacter Felis Infection}

The $H$. felis strain (ATCC 49197) was grown for $48 \mathrm{~h}$ at $37^{\circ} \mathrm{C}$ under microaerobic conditions on $5 \%$ lysed horse blood agar supplemented with antibiotics. Bacteria were harvested immediately before inoculation and adjusted to $10^{10}$ organisms $/ \mathrm{ml}$ in brainheart infusion broth. Five mice were inoculated with $H$. felis. The inoculum $(0.2 \mathrm{ml}$ of $H$. felis $)$ was delivered by gastric intubation into each test mouse three times at 2-day intervals using a sterile catheter. Animals were killed at 2 months postinoculation.

\section{Immunohistochemistry and Immunofluorescence}

A longitudinal section of the stomach (spanning both fundus and antrum) was fixed in $4 \%$ formaldehyde/PBS, paraffin-embedded, and $4 \mu \mathrm{m}$ sections were prepared. Antigen retrieval was performed for all antibodies (except for anti-intrinsic factor) by microwaving the specimens in $10 \mathrm{mM}$ citrate buffer ( $\mathrm{pH}$ 6.0) for $10 \mathrm{~min}$. Sections were immunostained with the following primary reagents at $4^{\circ} \mathrm{C}$ overnight: a rabbit antiserum against TFF2/SP (1:1000, a gift from Dr Andy Giraud, University of Melbourne, Melbourne, Australia); a rabbit antiserum against intrinsic factor (IF) $(1: 1000$, a gift from Dr David Alpers, Washington University, St Louis); a prediluted monoclonal antibody against Cdx2 (BioGenex, San Ramon, CA, USA); a polyclonal antibody against IFN $\gamma$ (1:100, Santa Cruz Biotechnology, Santa Cruz, CA, USA); a monoclonal antibody against MUC6 used at a 1:200 (Novocastra Laboratories Ltd), a monoclonal antibody against Ki67 (1:500, Pharmingen), and a plant lectin Griffonia Simplicifolia II (GSII, which recognizes $N$-acetyl-D-glucosamine (GlcNAc) at the end of $O$-glycosylated sugar chains ${ }^{17,18}$ 1:1000; Vector Laboratories, Burlingame, CA, USA). A 1:500 dilution of biotin-conjugated secondary antibodies were then added for $30 \mathrm{~min}$ at $25^{\circ} \mathrm{C}$ and visualized with avidin-biotin complexes using the Vectastain Elite ABC kit and diaminobenzidine (DAB) for the substrate (Vector Laboratories). For imunofluorescence, fluorescein isothiocyanate (FITC) or Texas Red-conjugated secondary antibodies were added for $30 \mathrm{~min}$ at $25^{\circ} \mathrm{C}$, before 
staining with 4',6-diamidino-2-phenylindole (DAPI) and mounting with aqueous mounting medium (Biomeda Corp, Foster City, CA, USA). Sections were also stained with hematoxylin and eosin (H\&E).

\section{Ribonuclease Protection Assay}

Riboprobes were generated from antisense templates for mCK-1 Multi-Probe Template Set (BD Pharmingen). All riboprobes were prepared using MAXIscript In vitro Transcription Kit (Ambion). Total RNA was hybridized for $16 \mathrm{~h}$ with riboprobes at $45^{\circ} \mathrm{C}$ in hybridization buffer (1 mM EDTA, $300 \mathrm{mM}$ sodium acetate, $\mathrm{pH} 6.4,100 \mathrm{mM}$ sodium citrate, $\mathrm{pH}$ $6.4,80 \%$ deionized formamide). After hybridization, the samples were digested at $37^{\circ} \mathrm{C}$ for $30 \mathrm{~min}$ in an RNase A/T1 mixture containing $60 \mathrm{U} / \mathrm{ml}$ RNase A, $250 \mathrm{U}$ RNase T1 (Ambion) in digestion buffer (300 mM NaCl, $10 \mathrm{mM}$ Tris, pH 7.4, $5 \mathrm{mM}$ EDTA). Protected fragments were precipitated in isopropanol, dissolved in loading buffer (95\% formamide, $0.025 \%$ xylene cyanol, $0.025 \%$ bromphenol blue, $0.5 \mathrm{mM}$ EDTA, $0.025 \%$ SDS), then resolved on a $6 \%$ polyacrylamide, $8 \mathrm{M}$ urea gel, and were visualized on a PhosphorImager and normalized to L32 and GAPDH mRNA levels.

\section{Cell Culture and Treatment}

The human gastric cancer cell line NCI-N87 was purchased from the American Type Culture Collection (ATCC, Manassas, VA, USA) and grown in Dulbecco's modified Eagle's medium (Life Technologies, Inc.) containing 10\% fetal calf serum, 100 $\mu \mathrm{g} / \mathrm{ml}$ penicillin, and $100 \mu \mathrm{g} / \mathrm{ml}$ streptomycin in a humidified atmosphere of $5 \% \mathrm{CO}_{2}$ and $95 \%$ air at $37^{\circ} \mathrm{C}$. The cells $\left(2 \times 10^{6} / \mathrm{ml}\right)$ were plated on $60-\mathrm{mm}$ culture dishes and then stimulated with recombinant mouse IFN $\gamma$ (R\&D System, $10 \mathrm{U} / \mathrm{ml}$ ) for the indicated time periods.

\section{RT-PCR}

Total RNA was isolated from gastric tissues or cultured cells, using TRIzol Reagent (Gibco). Total RNA ( $5 \mu \mathrm{g})$ was reverse transcribed into cDNA using Oligo $(\mathrm{dT})_{15}$ primers and Superscript II reverse transcriptase (Life Technology). The following primer pairs were used for PCR reactions: human (h) MUC6 (forward: 5'-GGCGCTGGACCCCCTCTC-3' and reverse: 5'-GCAGCCCGCGTA ATCACAAGT-3'); hTFF2 (forward: 5'-TGAGCCCCCATAACAGGACG AAC- $3^{\prime}$ and reverse: 5'-TGATGCCCGGGTAGCCA CAGT-3'); hPepsinogen I (PGA) (forward: $5^{\prime}$-CAGC GCCGATGACAAGAGT- $3^{\prime}$ and reverse: $5^{\prime}$-AGGCTGC TGATGGCT GAG-3'); hPepsinogen II (PGC) (forward: 5'-CACCGGCTTCTTTGGCTATGAC- $3^{\prime}$ and reverse: 5'-CCCCGTGTACAGGCTGCTATCCA-3'); hIntrinsic factor (forward: $5^{\prime}$-TGCCCCAGGTCACTTGTAG-3' and reverse: $5^{\prime}$-CATTTTCCGC GATATTGTTGAT-3'); hActin forward: $5^{\prime}$-ATGATATCGCCGCGCTCGTCGT C-3' and reverse: $5^{\prime}$-CTCGTCGCCCACATAGGAATC$3^{\prime}$ ); and mouse IFN $\gamma$ (forward: $5^{\prime}$-TCAGCAACAGCA AGGCGA AAAAG- $3^{\prime}$, reverse: 5'-ACCCCGAATCAG CAGCG ACTC- $3^{\prime}$ ). All of the primers were designed to cross exon-intron borders, to exclude the amplification of genomic DNA. Human/mouse actin was used to normalize the amount of mRNA amplified by specific primers.

\section{Quantitative RT-PCR}

The PCR primer sequences for IFN $\gamma$ and actin were as described above. The fluorogenic probe $(100 \mathrm{nM}$, containing the reporter dye (FAM) covalently attached to the 5'-end, Research Genetics Inc., Huntsville, AL, USA) was used in all quantitative PCR amplifications. The reactions were carried out in a total volume of $25 \mu \mathrm{l}$ in triplicate wells in a Biorad-I Cycler (BioRad, Hercules, CA, USA). The fold change for each $\mathrm{G}-/-$ mouse was calculated as suggested by Livak and Schmittgen: ${ }^{19} 2^{\Delta \Delta C_{\mathrm{T}}}$ $=$ fold change and $\Delta \Delta C_{\mathrm{T}}=\left(C_{\mathrm{T}, \text { Target }}-C_{\mathrm{T}, \text { Actin }}\right)_{G-{ }_{-}-}$ $\left(C_{\mathrm{T}, \text { Target }},-C_{\mathrm{T}, \mathrm{Actin}}\right)_{\mathrm{W}_{\mathrm{T}}}$, where $C_{\mathrm{T}}=$ threshold cycle and $\left(C_{\mathrm{T}, \text { Target }},-C_{\mathrm{T}, \mathrm{Actin}}\right)_{\mathrm{W}_{\mathrm{T}}}=$ mean value for seven WT mice.

\section{Western Blotting}

NCI-N87 cells with or without IFN $\gamma$ treatment were scraped into M-per lysis buffer (Pierce) supplemented with protease inhibitors. The culture supernatant was concentrated using Ultrafree Centrifugal Filter (Millipore, Bedford, MA, USA). After centrifuging the lysate for $10 \mathrm{~min}$ at $10000 \mathrm{~g}$ to remove nuclei, $30 \mu \mathrm{g}$ of total cell extracts or concentrated supernatant were subjected to SDS-PAGE (4-20\% (w/v), acrylamide) followed by electrotransfer onto PVDF membranes. A monoclonal antibody (Novocastra Laboratories Ltd) was used to detect MUC6 at 1:200 dilution. Phosphorylated STAT1 was detected by immunoblotting using Phospho-Stat1 (Tyr701) antibody (Cell Signaling, Bedford, MA, USA). The signals were visualized with an ECL detection system (Amersham). The membrane was stripped and reblotted with an antibody against STAT1 (Cell Signaling), and a monoclonal antibody against GAPDH (Santa Cruz Biotechnology) to normalize the input.

\section{Flow Cytometry}

NCI-N87 cells with or without IFN $\gamma(10 \mathrm{U} / \mathrm{ml})$ treatment for $24 \mathrm{~h}$ were trypsinized and washed twice in PBS/0.5\% BSA buffer. Forward scatter was measured using FACScan (Beckman Dickson). Data were analyzed using CellQuest Software (Becton Dickinson). The difference in the mean value of the forward scatter between treated and untreated cells was used to determine the difference in cell size. 


\section{Statistical Analysis}

The significance of the results was determined using the unpaired $t$-test from a commercially available software Prism 3 (GraphPad Software, San Diego, CA, USA). A $P$-value $<0.05$ was considered significant.

\section{Results}

\section{Appearance of Fundic Mucous Cells Coincides with an Inflammatory Infiltrate}

At 16 weeks of age, clusters of mucous cells became visible in the middle of the fundic mucosa of $\mathrm{G}-/-$ mice (Figure 1). These cells had a foamy appearance with abundant cytoplasm (Figure 1b), which mimicked the morphology of cells in the duodenal Brunner's glands (Figure 1c). These mucous cells stained for neutral mucin with periodic acid-Schiffstain (PAS) (Figure 1e), as was also observed in cells of the Brunner's gland (Figure 1f). In the normal fundic mucosa, PAS-positive mucous neck cells were much less prominent (Figure 1d). There was little evidence of acidic mucins (blue) in the stomach of WT or G-/- mice (Figure 1d and e), which was clearly present in epithelial cells of the duodenum (Figure 1f). Gastric mucosal inflammation in the form of lymphoid aggregates was found near the prominent fundic mucous cells in G-/- mice (Figure 1b).

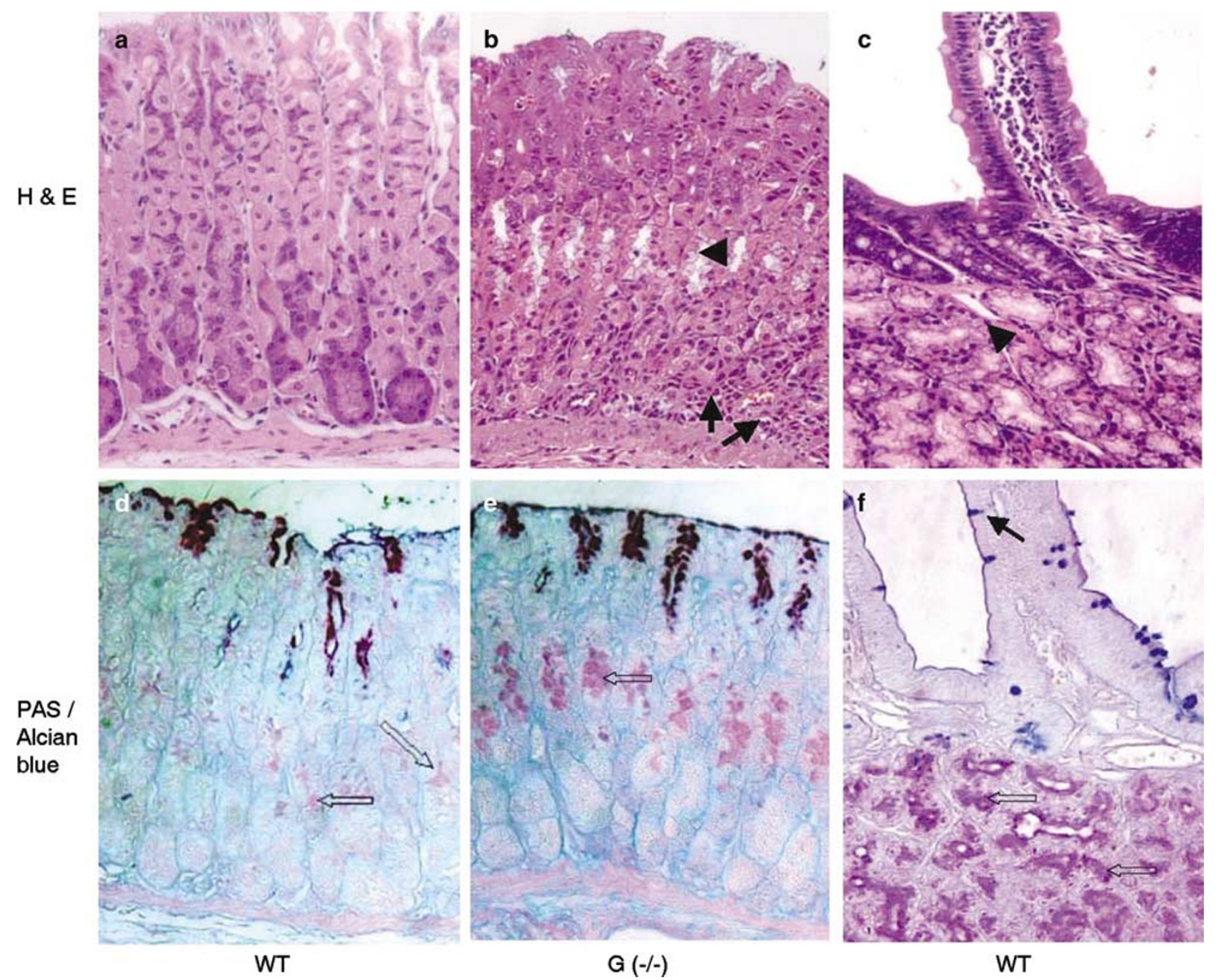

Figure 1 An inflammatory infiltrate accompanies the emergence of a prominent mucous cell lineage in the G-/- fundic mucosa. Representative H\&E and PAS/alcian blue-stained sections of stomachs from 4-month-old WT (a and d) and G-/- (b and e) mice. The large foamy mucous cells in G-/- mice (b, arrowhead) morphologically resemble cells of the Brunner's gland (c, arrowhead). Increasing prominence of PAS-positive (Stains neutral mucin, open arrows) cells were seen in the neck region of the G-/- fundic mucosa (e), in comparison with WT (d). Mucous cells in the Brunner's gland are also PAS positive (f). Acidic mucins that stained intestinal goblet cells blue (arrow) were not present in the fundus of WT (d) and $G-/-(\mathbf{e})$ mice. An inflammatory infiltrate was observed at the bottom of fundic glands in $\mathrm{G}-/$ - mice (b, arrows). 
The Prominent Mucous Cells in the Fundus of G-/- Mice are Phenotypical Mucous Neck Cells

Since the mucous cell lineage described above was one of the earliest histological changes in the gastric mucosa of $\mathrm{G}-/$ - mice, it was of interest to identify protein markers for these cells. Trefoil factor 2 (TFF2/SP) is known to mark a morphologically similar mucous cell lineage called SPEM in the fundic mucosa. ${ }^{7,9}$ Indeed, we also found that TFF2 antibody labeled the clusters of mucous cells in the middle of $\mathrm{G}-/$ - fundic glands (Figure 2a and i). In addition, the plant lectin GSII, (Figure $2 \mathrm{e}$ and $\mathrm{i}$ ), and an antibody to MUC6 (Figure 3a), stained the same cell population. A similar distribution of the three markers was also observed in fundic mucous neck cells (Figure 2b, f and j; Figure $3 \mathrm{~b}$ and e) of WT mice. However, no difference in the distribution pattern was detected in the pyloric gland of the $\mathrm{G}-/-$ antrum at 4 months (Figure 2c, $\mathrm{g}$ and $\mathrm{k}$ ), in comparison to WT mice (data not shown). Collectively, these results suggested that the prominent mucous cells appearing in the $\mathrm{G}-/$ - fundus are phenotypically related to the mucous neck cell lineage. Interestingly, all three markers also recognized cells in the Brunner's glands of the duodenum (Figure 2d, h and l; Figure 3c and f).

\section{Fundic Mucous Cells in G-/- Mice do not Express Cdx2}

Since these emergent fundic mucous cells expressed the same mucus-related proteins as the Brunner's glands, it raised the possibility that the gastric lineage shares small intestinal characteristics. When
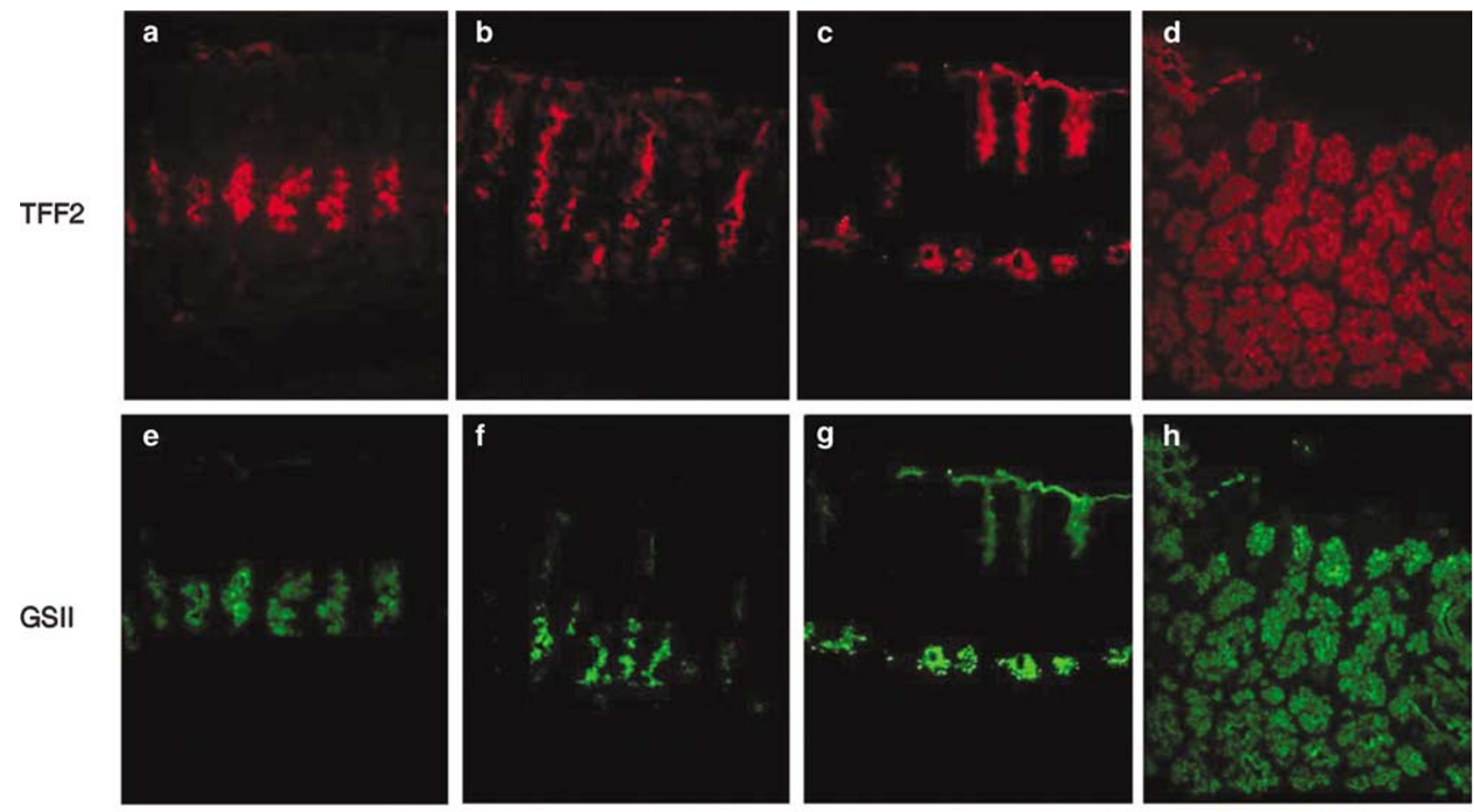

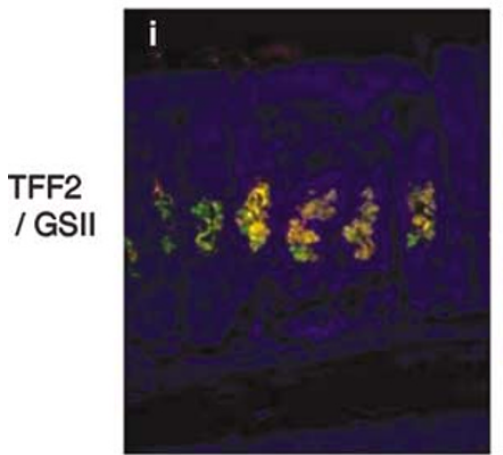

Fundus $\mathrm{G}(-/-)$

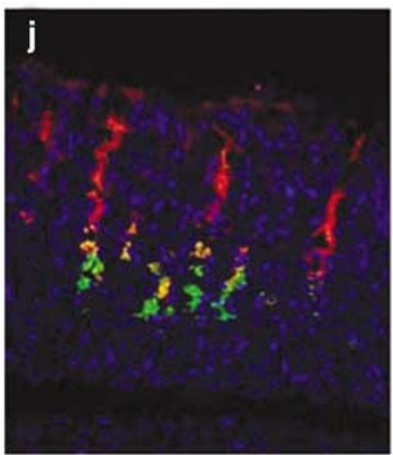

Fundus

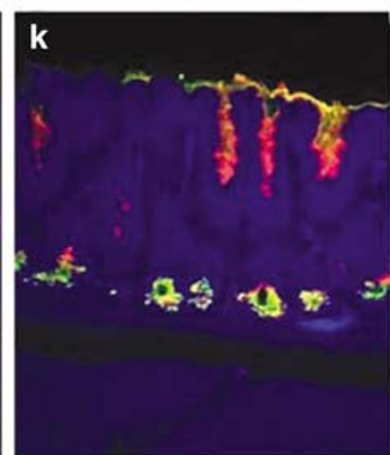

Antrum

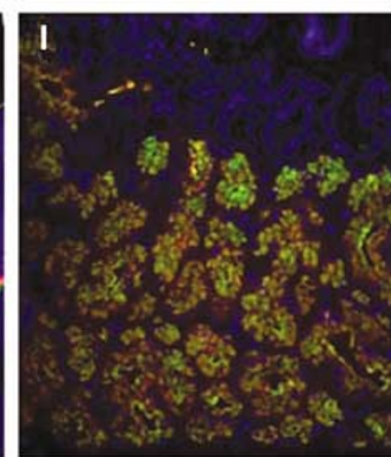

Brunner's gland WT

Figure 2 Distribution of TFF2 and GSII-positive cells in WT and G-/- mice. A polyclonal $\alpha$-TFF2 antibody (a, Texas Red) and the fluorescent-tagged plant lectin GSII (e, FITC) stained mucous neck cells in the fundic mucosa of G-/- mice with high specificity. Both reagents also stained the mucous neck cells (b and f) and the Brunner's gland ( $\mathbf{d}$ and $\mathbf{h}$ ) in WT mice, and pyloric gland cells (c and g) of the G-/- antrum. Merging of images (i-l) showed overlap of TFF2 and GSII staining. 

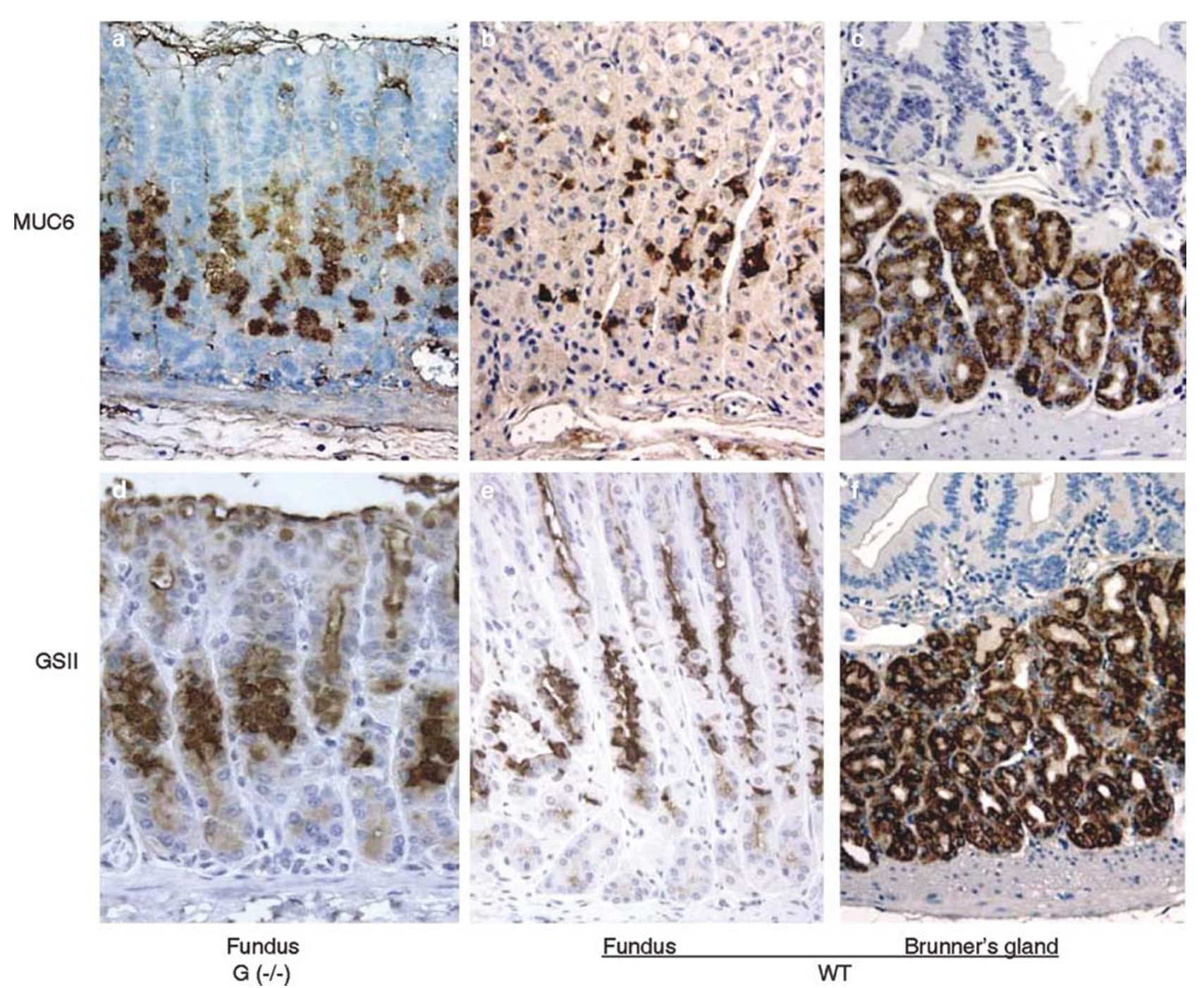

Figure 3 Distribution of GSII and MUC6 in WT and G-/- mice. Immunohistochemical staining showed similar staining pattern in the fundic mucosa and the Brunner's gland in G-/- and WT mice, using a monoclonal $\alpha$-MUC6 antibody (a and b) and a plant lectin GSII (d and $\mathbf{e}$ ). Both reagents recognized the metaplastic cells in $\mathrm{G}-/$ - mice with high specificity (c and f).

we analyzed the distribution of the homeobox protein Cdx2, a transcription factor capable of inducing intestinal metaplasia in the stomach, ${ }^{20-22}$ we found strong nuclear Cdx2 staining in the epithelial cells of the proximal small intestine as well as cells of the Brunner's glands (Figure 4a) as previously reported. ${ }^{21}$ However, no Cdx2 protein was detected in normal gastric mucosa (data not shown), nor in the prominent fundic mucous cells of the $\mathrm{G}-/-$ mice (Figure 4b), suggesting that these cells maintain their gastric identity, instead of acquiring an intestinal identity as the cells of the Brunner's gland.

\section{Fundic Gland Mucous Cells in G-/- Mice do not Express Chief Cell Markers}

Since some SPEM cells have been found to coexpress TFF2 and intrinsic factor (IF), ${ }^{11}$ a specific secretory product of mouse chief cells, we examined whether IF was also expressed in the expanded fundic mucous cell compartment of the $\mathrm{G}-/$ - mice. Using double-fluorescent labeling with GSII and rabbit- $\alpha$-IF, we found little overlap of GSII-positive cells with IF-positive cells in either WT (Figure 4c) or G-/- mice (Figure 4d). These results suggested that the prominent mucous cell lineage, present in the middle of fundic glands in $\mathrm{G}-/$ - mice, rarely shares markers with the chief cell lineage. Overlap between these two cell populations was not observed in another mouse model during gastric inflammation progressing to transformation, in which STAT3 activity was increased. ${ }^{13}$

\section{An Increase in Mucosal Proliferation in the Fundus of $\mathbf{G}-/-$ and $H$. Felis-Infected Mice}

The expansion of the mucous neck cell compartment in G-/- mice may reflect hypertrophy, 
708
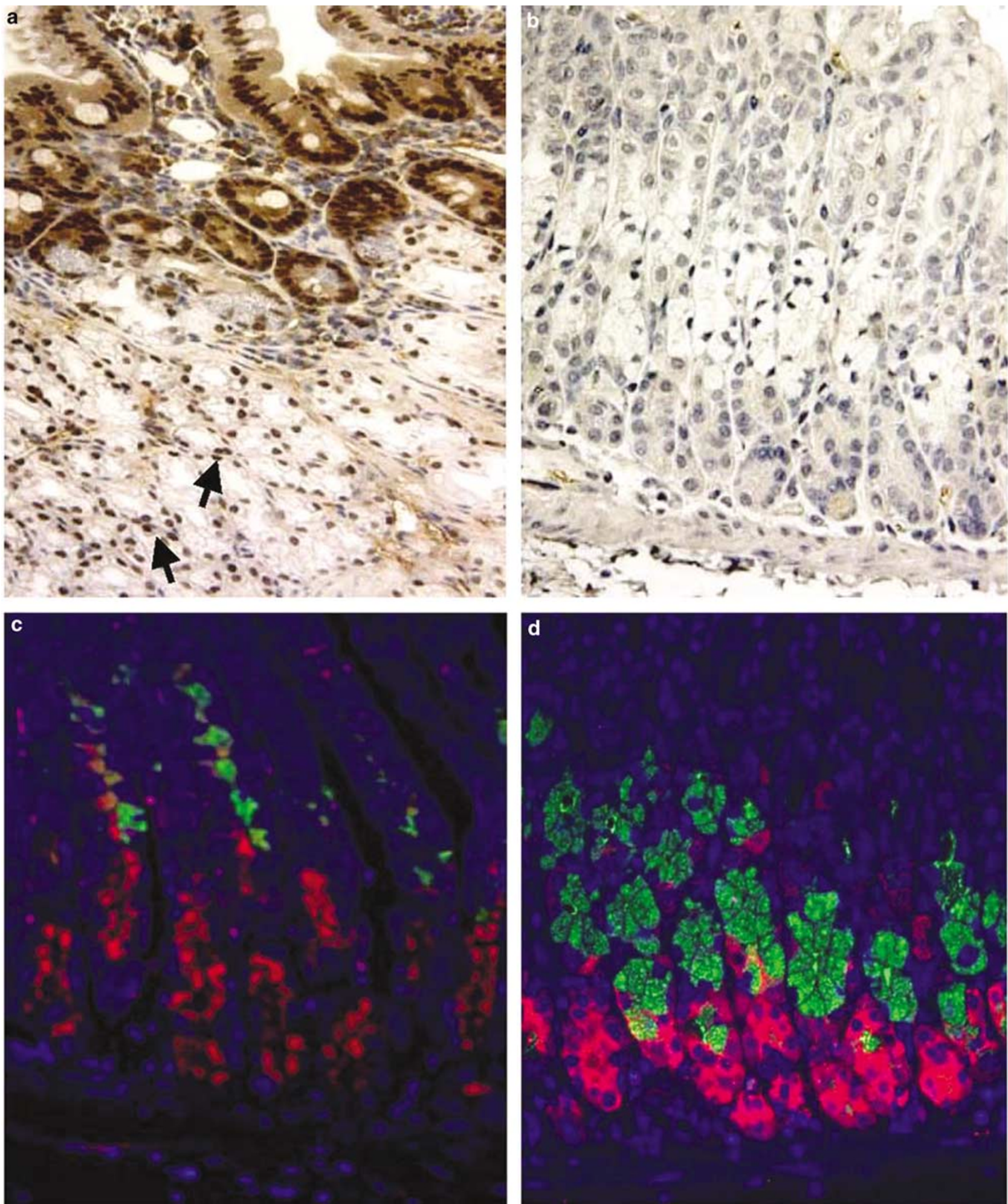

Figure 4 Absence of intestinal and chief cell markers in the expanded mucous neck cell compartment in G-/- mice. Immunohistochemical staining of $\mathrm{Cdx} 2$, an intestine-specific transcription factor, in the duodenum of WT mice (a), was absent in the mucous cells of the G-/ - fundus (b). Arrows indicate the nuclear location of Cdx2 in cells of the Brunner's gland. Double immunofluorescence showed the distribution of GSII (FITC)-positive mucous neck cells and IF (Texas Red)-positive chief cells in WT (c) and $\mathrm{G}-/-(\mathbf{d})$ mice.

hyperplasia or both. To help distinguish these possible mechanisms, we double-labeled the gastric mucosa of uninfected $\mathrm{WT}, \mathrm{G}-/-$ and $H$. felis- infected mice with GSII (to identify the mucous neck cells) and with Ki67 (to show cell proliferation). An increase in the proliferation index was 
observed in the fundic glands of $\mathrm{G}-/-$ mice compared to WT mice, although the difference was not statistically significant $(3.25 \pm 0.54 /$ gland $v s$ $5.37 \pm 0.72 /$ gland, Figure $5 \mathrm{a}$ and b). Ki67-positive cells (red, nuclear) were largely restricted to the isthmus region of both the WT and G-/ - fundi, and were rarely observed to colocalize with either GSIIpositive cells (green, cytoplasmic label), or the lower half of the fundic gland where the chief cells are located. These results suggested that enhanced proliferation occurring in stem cells, but not the differentiating progenitors of mucous neck cells, may be responsible for the expansion of this cell lineage in young $\mathrm{G}-/-$ mice. In $H$. felis-infected mice, the Ki67 label $(17.88 \pm 2.36 /$ gland $)$ was sixfold than what was observed in WT mice $(P<0.01)$ (Figure 5c). In addition, proliferating cells were detected not only in the isthmus but also colocalized with GSII-staining cells in the lower half of the hyperplastic glands. In contrast to $\mathrm{G}-/$ - mice, these data indicated that in the Helicobacter-infected fundic mucosa, a significant increase in proliferation occurred within the neck cell lineage, which may explain the more profound expansion of the neck cell-compartment observed in these mice.

\section{IFN $\gamma$ Expression is Elevated in the Gastric Mucosa of $\mathbf{G}-/-$ Mouse}

In an effort to identify the molecular mechanisms responsible for hypertrophy of mucous cells in the G-/ - stomach, we compared the cytokine profiles from the gastric mucosa of $\mathrm{WT}$ and $\mathrm{G}-/$ - mice using RNase protection assays (RPA). IFN $\gamma$, the predominant cytokine generated in a Th1 immune response, was the primary cytokine significantly elevated in G-/- mice (Figure 6a). A slight increase in TNF $\alpha$ mRNA was also detected. No detectable change in signal intensity was found for the other cytokines including TNF $\beta$, LT $\beta$, TGF $\beta 1$, TGF $\beta 2$, IL-6 and MIF. Analysis using another set of probes also showed no significant induction of IL-4, IL-5, IL-10, IL-13, IL-15, IL-9, IL-2 and IL-6 in the gastric mucosa of G-/- mice (data not shown).

Additional assays were performed to confirm the findings of the RPA. Semiquantitative RT-PCR demonstrated a marked increase in IFN $\gamma$ transcript levels in $\mathrm{G}-/$ - stomachs as a function of the age of the mice (Figure 6b). Real-time PCR quantification confirmed a 7-12-fold increase in INF $\gamma$ gene expres-

Figure 5 Differential changes in gastric mucosal proliferation in G-/ - and H. felis-infected mice. Ki67-positive cells (Texas red) were restricted to the isthmus region of the fundic mucosa, primarily above the GSII-positive neck cells (FITC) in WT (a) and in G-/- mice (b). Ki67-positive cells were present in the bottom half of fundic glands, and colocalization with the GSII-positive neck cells (arrows) was found in H. felis-infected mice (c). The mean number \pm s.e.m. of Ki67-positive cells/gland in WT, G-/and $H$. felis-infected mice $(n=8)$ were counted and are shown in the representative photographs. ${ }^{*} P<0.01$ vs WT.
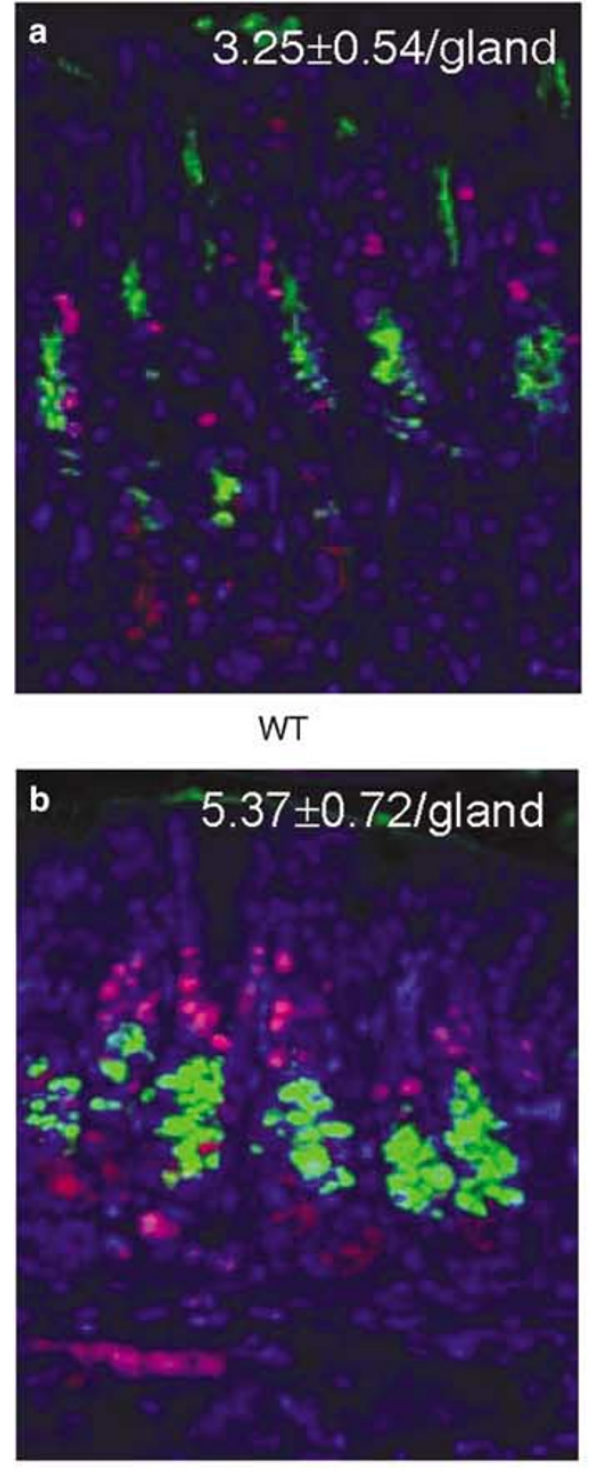

$\mathrm{G}(-/-)$

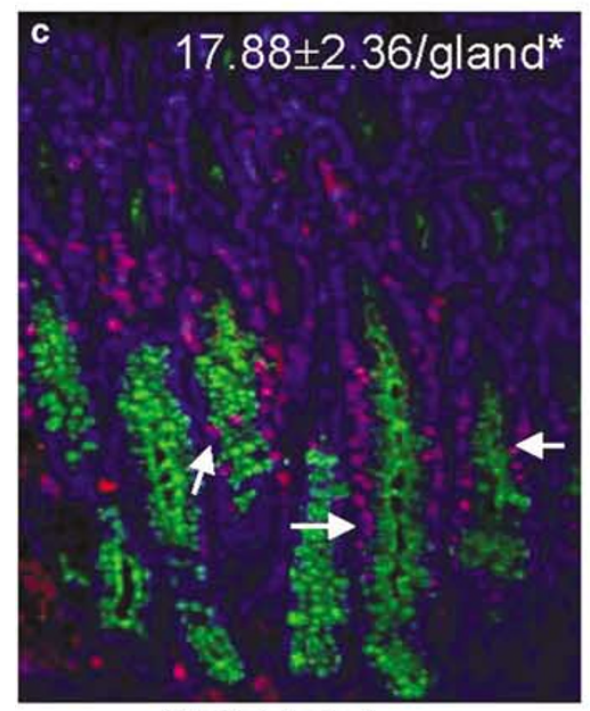

H.felis-infected 

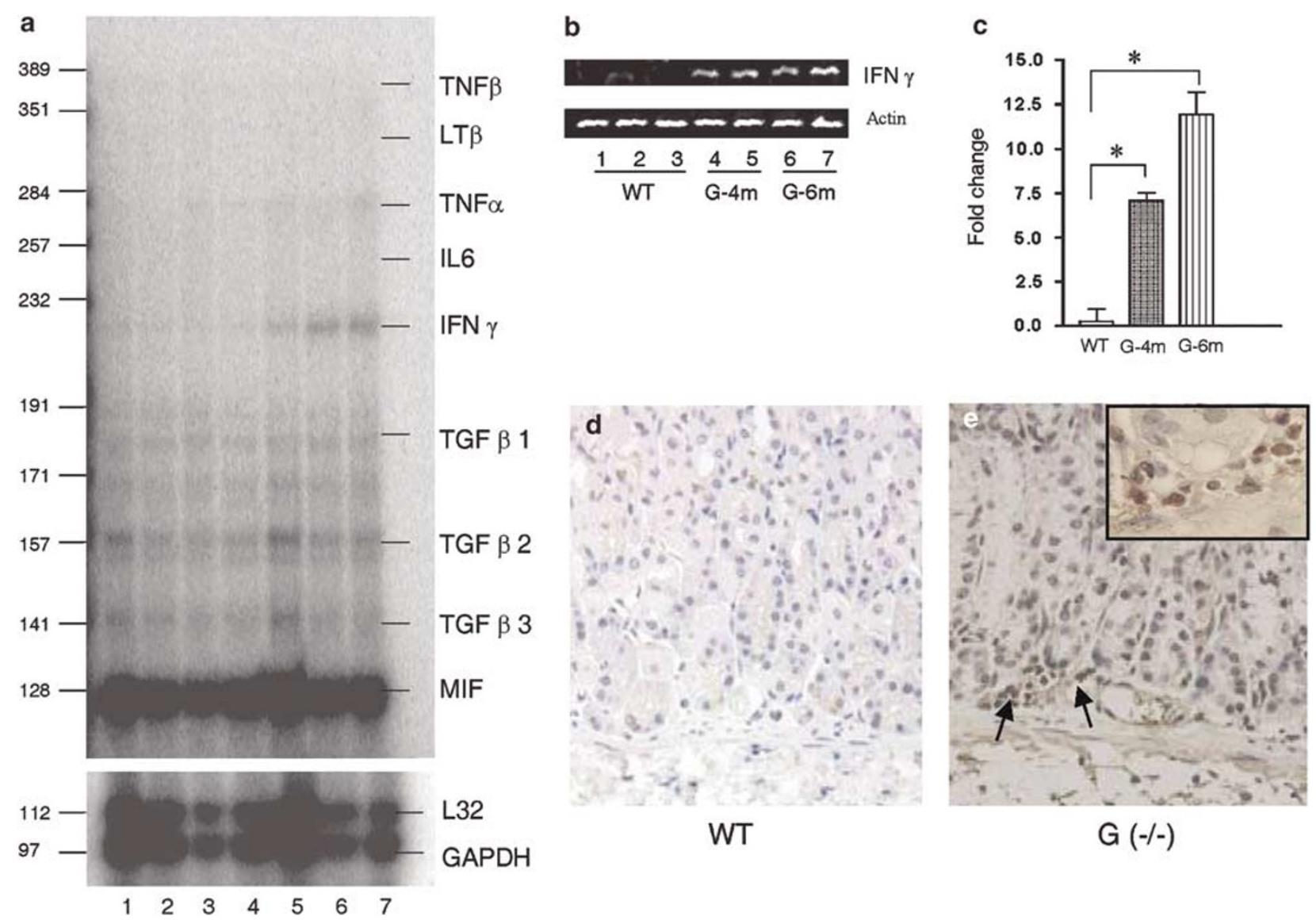

Figure 6 Induction of IFN $\gamma$ expression in the inflamed gastric mucosa of G-/- mice. (a) RNase protection assays (RPA) were used to measure the mRNA expression of cytokines in the G-/- stomach. RNA from the gastric mucosa: lanes 1-3, WT; lanes 4-5: G-/- 4 months; lanes 6-7: G-I-6 months. (b) Semiquantitative RT-PCR was performed on RNA extracted from the gastric mucosa of WT and G-/- mice. Actin was used to normalize the amount of RNA from each sample. (c) Real-time PCR quantification of IFN $\gamma$ mRNA expression. The mean \pm s.e.m. for seven mice in each group is shown. ${ }^{*} P<0.01$ vs WT mice (unpaired $t$-test). Immunostaining of the gastric tissue of WT (d) and G-/ - (e) mice using an IFN $\gamma$ antibody, indicated IFN $\gamma$-positive inflammatory cells (arrows) in the mucosal compartment (inset, $\times 1000$ ) in $\mathrm{G}-/-$ mice.

sion in 4- and 6-month old G-/- mice (Figure 6c). No IFN $\gamma$ was detected in the gastric mucosa of WT mice by immunostaining (Figure 6d). In contrast, some lymphocytes infiltrating into the mucosa of the $\mathrm{G}-/$ - gastric mice were IFN $\gamma$-positive (Figure $6 e)$, suggesting that the IFN $\gamma$ induced was from the inflammatory cells.

\section{IFN $\gamma$ Administration Recapitulates the Gastric Phenotype of the G-/- and H. Felis-Infected Mice}

To study the effect of IFN $\gamma$ alone on the gastric mucosa, WT mice were infused with the cytokine for 2 weeks. Hematoxylin and eosin (H\&E) staining revealed the presence of clusters of clear mucous cells in the middle of the glandular mucosa (Figure 7d), similar to the prominent mucous cells that emerged in the G-/- mice (Figure $7 \mathrm{~g}$ ). Immunohistochemical staining confirmed that these cells were positive for MUC6 (Figure 7e), TFF2 (Figure 7f) and GSII (Figure 5c), consistent with the molecular features detected in 4-month-old G-/- mice (Figure $7 \mathrm{~h}$ and i) and mice infected with $H$. felis for 2 months (Figure $7 \mathrm{k}$ and $\mathrm{l}$ ), as well as mucous neck cells in WT mice (Figure $7 \mathrm{~b}$ and $\mathrm{c}$ ). However, the mucous cell expansion in infected mucosa occupied

\footnotetext{
Figure 7 IFN $\gamma$ administration induces mucosal changes phenotypically similar to G-/- mice. H\&E staining showed that IFN $\gamma$ infusion for 14 days led to the emergence of large and clear mucous cells in the middle of the fundic glands in WT mice (d, arrows), morphologically similar to the prominent mucous cells seen in 4-month-old G-/- mice (g, arrows) and mice infected with $H$. felis for 2 months (j, arrow), which were not present in the PBS-infused WT control mice (a). The clusters of enlarged mucous cells in the three animal models were all stained positive for both MUC6 (e, h and $\mathbf{k}$ ) and TFF2 (f, $\mathbf{i}$ and $\mathbf{l}$ ), which also marked mucous neck cells in normal gastric mucosa (b and $\mathbf{c}$ ). An inflammatory infiltrate was observed at the bottom of gastric mucosa and in submucosa of $H$. felis-infected mice (j, open arrows).
} 

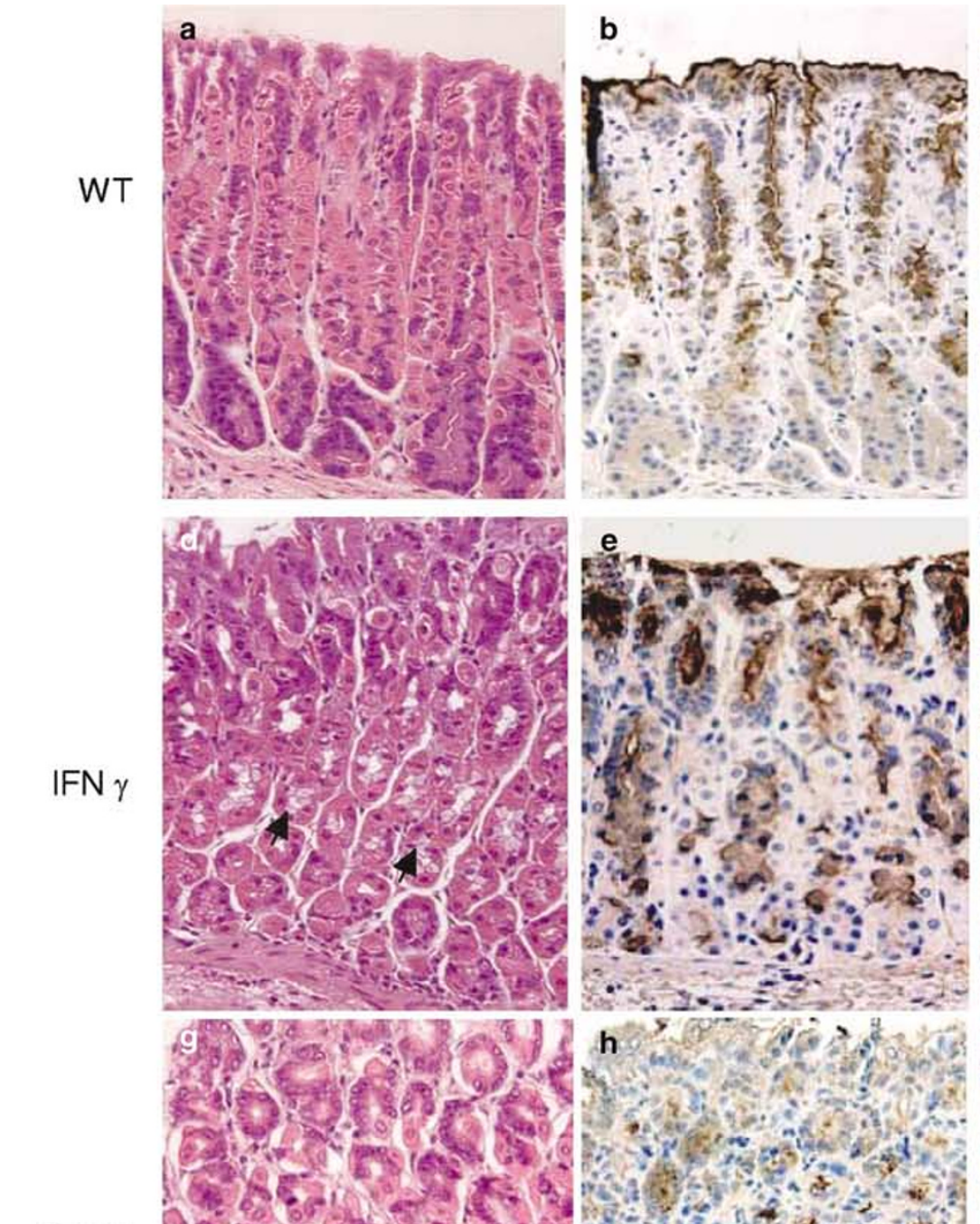

G (-/-)

H Felisinfected
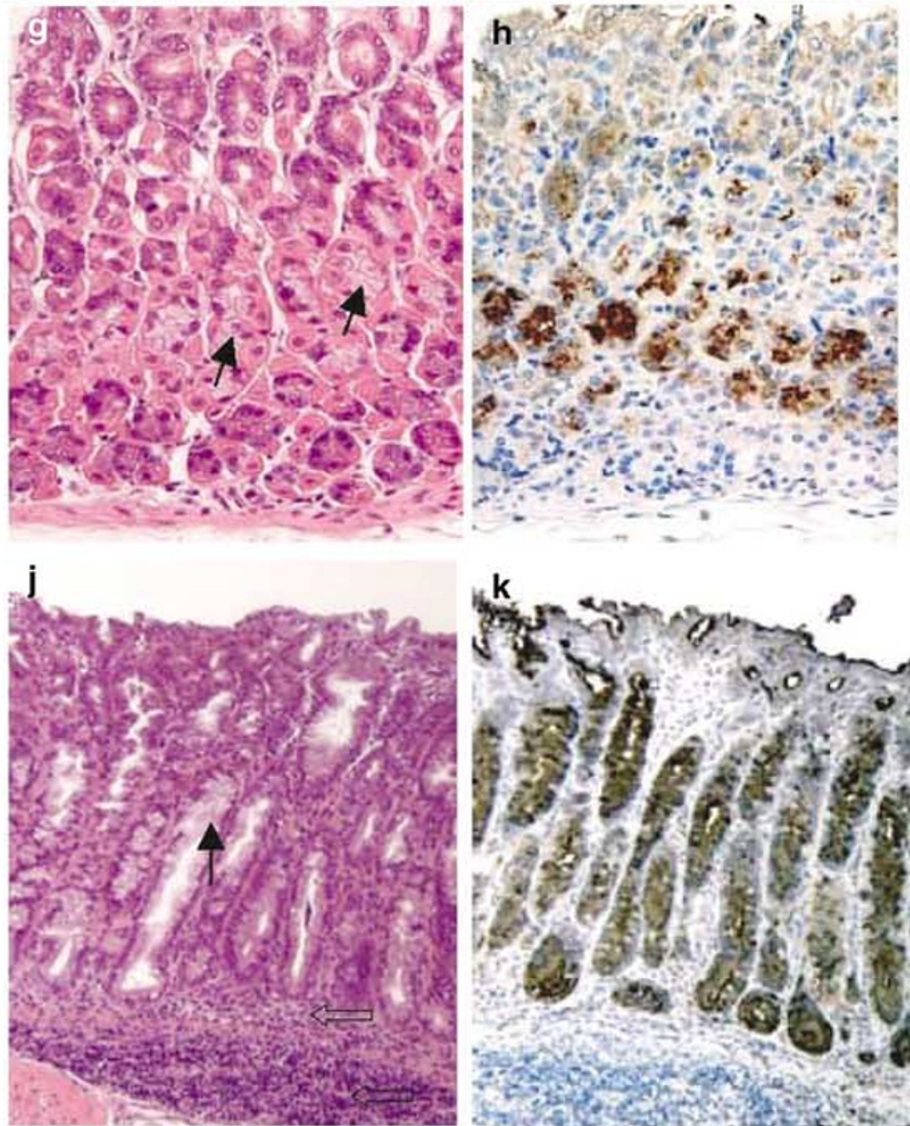

$H \& E$

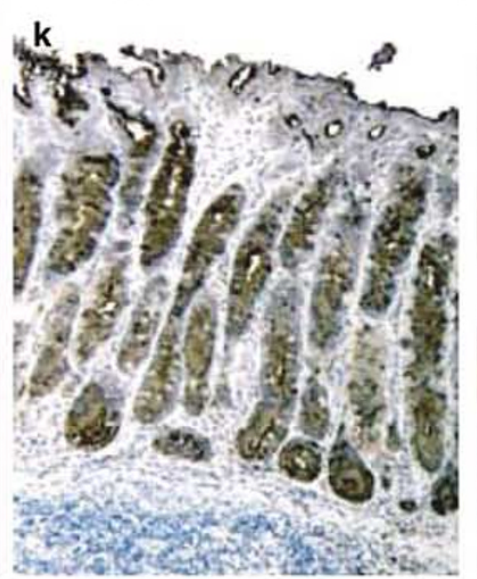

MUC6
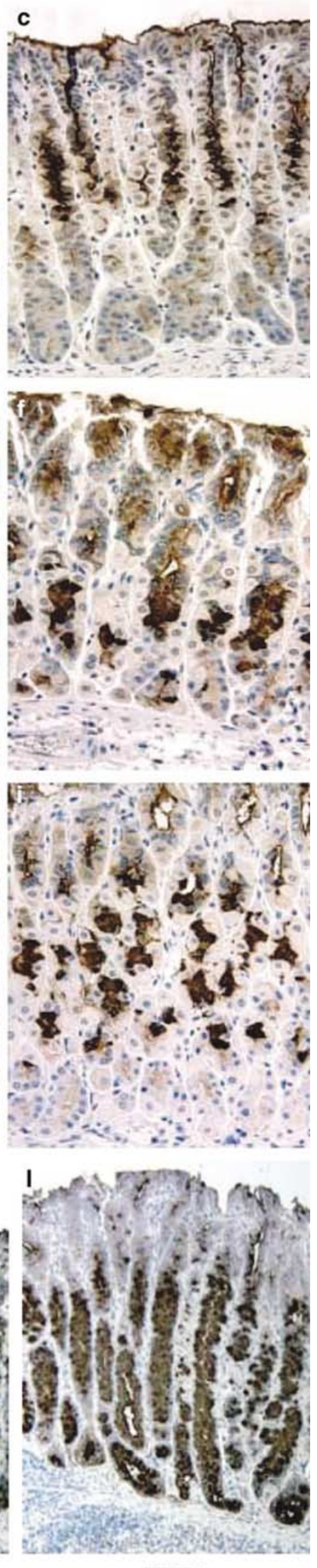

TFF2 
a greater portion of the fundic glands including the base of the gland, possibly due to the more extensive tissue inflammation (Figure 7j). These data suggested that IFN $\gamma$ infusion, and inflammation in G-/ - and $H$. felis-infected mice, all resulted in enlargement of the mucous neck cell compartment, although to different extents due to different mechanisms (ie, hypertrophy vs hyperplasia).

\section{IFN $\gamma$ Induces the Expression of MUC6 and TFF2, and Hypertrophy}

To more effectively study whether IFN $\gamma$ elicits a direct effect on mucous neck cells, we performed in vitro analysis on the human gastric cell line NCI-N87. This cell line has been shown to exhibit a mucopeptic phenotype, that is, producing MUC6 glycoprotein and pepsinogen. ${ }^{23}$ We demonstrated IFN $\gamma$ induction of both TFF2 and MUC6 gene expression in NCI-N87 cells (Figure 8a). A time course study revealed that the TFF2 induction occurred within $6 \mathrm{~h}$ of IFN $\gamma$ treatment. This was not surprising since TFF2 has been reported to be an immediate-early gene, in response to EGF- or autoinduction, ${ }^{24,25}$ but has not been shown to be regulated by proinflammatory cytokines. Expression of the pepsinogen II (PGC), pepsinogen I (PGA), intrinsic factor and $\mathrm{H}+, \mathrm{K}+$-ATPase genes was also detected in this gastric cancer cell line by RT-PCR (Figure 8a). PGC, but not PGA, was induced by IFN $\gamma$ (Figure 8a). Western blot analysis demonstrated a marked induction in phosphorylated STAT1, indicating STAT1 activation within $6 \mathrm{~h}$ of $\mathrm{IFN} \gamma$ treatment. A more significant increase in the levels of STAT1 protein and the secretion of MUC6 into the media induced by IFN $\gamma$ was observed at $24 \mathrm{~h}$ (Figure 8b). Consistent with MUC6 release, an increase in mucus secretion was also detected by immunocytochemical staining for MUC6 (Figure 8c and d). Interestingly, we also found that IFN $\gamma$ induction of mucus secretion, TFF2 and MUC6 expression, coincided with an increase in the size of NCI-N87 cells relative to vehicle-treated cells. Cell size was determined by analyzing the mean value of forward scatter using flow cytometry (Figure $8 \mathrm{e})$. An $11 \pm 3.2 \%(n=4)$ increase in cell size was determined by this method (Figure 8f). This increase in cell size was reminiscent of what we observed in vivo in the $\mathrm{G}-/-$ and $H$. felis-infected mouse models, showing hypertrophy of the mucous neck cells.

\section{Discussion}

In the present study, we demonstrated that the prominent mucous cell lineage that emerges in the fundus of $\mathrm{G}-/-$ mice and $H$. felis-infected mice is due to expansion of the mucous neck cell compartment. This conclusion is based on the fact that three mucous neck cell markers (TFF2/GSII/MUC6, as shown here and previously ${ }^{26-29}$ ), but not Cdx2, labeled this expanded compartment in both animal models. Previously, gastric mucosal changes with histological features of Brunner's gland cells were designated as metaplastic. Indeed, we demonstrate that both the mucous neck and Brunner's gland cells produce TFF2 and MUC6 as well as stain for GSII. However, the lack of intestine-specific transcription factor $\mathrm{Cdx} 2$ in the expanded mucous neck cell compartment, suggests that these cells retain a distinct gastric phenotype rather than converting to an intestinal lineage. Therefore histology alone, and overlap in mucous secretory and PAS staining patterns are not sufficient to determine whether one differentiated cell type has converted to another. This concept of an expanded mucous cell compartment is consistent with two other previously reported mouse models, the $H$. felis-infected and mice with the Kcnq1 potassium channel locus mutated. Both of these models exhibit a mucous cell lineage morphologically similar to SPEM and similar to the expanded mucous neck cell compartment we observed in the $\mathrm{G}-/-$ mice. ${ }^{8,12}$

There are three possible mechanisms by which the mucous neck cell compartment may expand. Two of these mechanisms were observed in the models examined in this study. First is an increase in cell size without Ki67 labeling (hypertrophy), observed in the middle of the fundic gland of $\mathrm{G}-/-$ mice. Our in vitro study also showed the enlargement of a MUC6/TFF2-positive cell line, accompanying the induction of mucus production. However, we cannot exclude a second possibility that there is an increased commitment of hyperplastic stem/ progenitor cells to this lineage, due to chronic mucosal inflammation or injury. A third mechanism is hyperplasia within the mucous neck cell compartment, demonstrated by Ki67 labeling of GSIIpositive cells. This was observed in $H$. felis-infected mice where the stomach exhibits a more extensive inflammatory infiltrate. The present study of both animal models, therefore, reaffirms that these apparently aberrant mucous cells are not metaplastic in the strict sense of the word, but instead represent an increase in the size and/or number of the normal mucous neck cell lineage.

When comparing the distribution of the enlarged mucous neck cells in different mouse models, we noticed its close relationship to the preservation of chief cells, which occupy the bottom third of fundic glands in the normal stomach. Although mucous neck cells are thought to be a separate and distinct cell lineage, ${ }^{30}$ based on the presence of heterogeneous granules in their cytoplasm, they have also been proposed to be a transitional cell type emerging from mucosal stem cells and terminally differentiating into chief cells. ${ }^{31-33}$ We detected basal orientation of the expanding neck cell compartment in $H$. felis-infected mice, which was accompanied by a profound loss of chief cells. Examples of basaloriented expansion of TFF2-expressing mucous cells accompanying a severe loss of chief cells has 
a
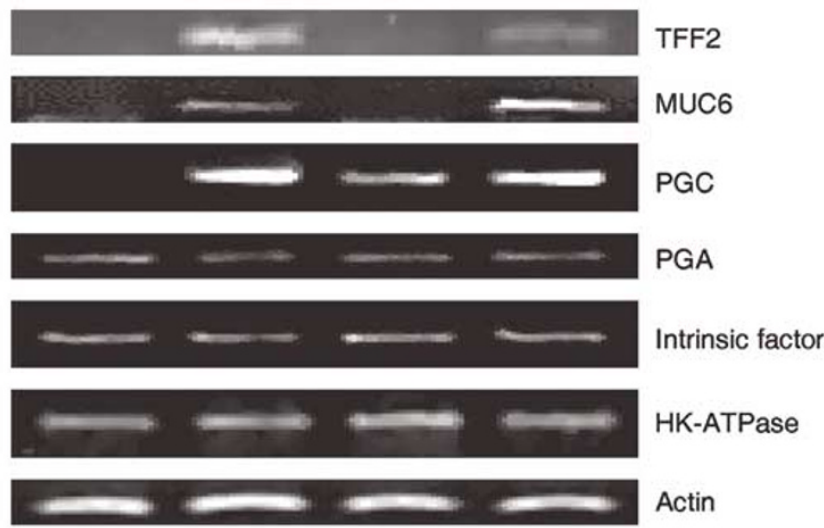

IFN $\gamma$ :

$\frac{(-)}{6 \mathrm{~h}^{(+)}}$

$\frac{(-)}{24 \mathrm{~h}^{(+)}}$

( - )

c IFN $\gamma$ :

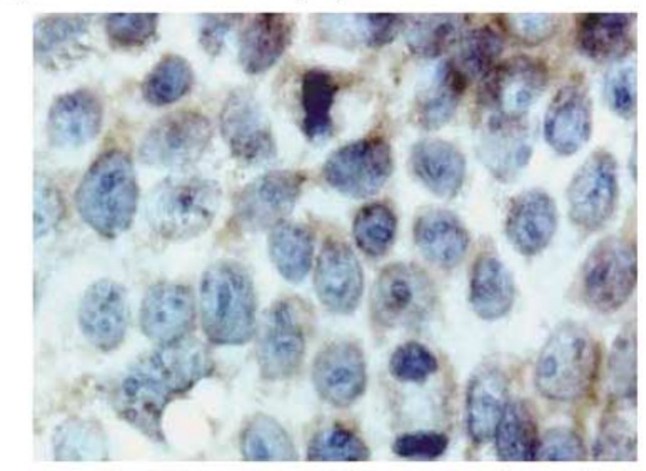

e

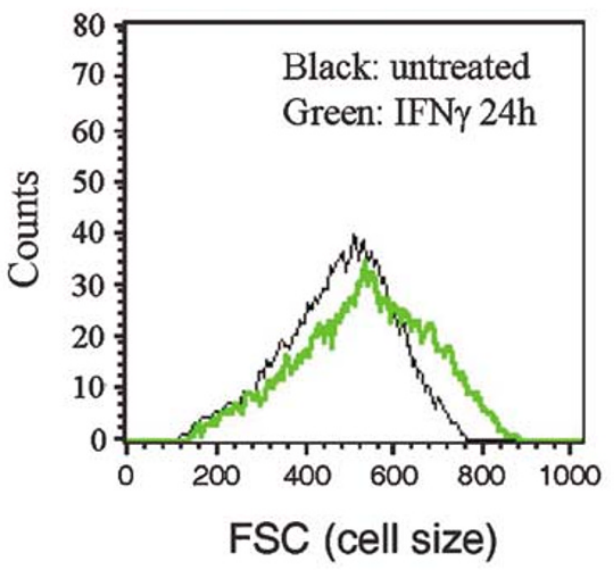

b

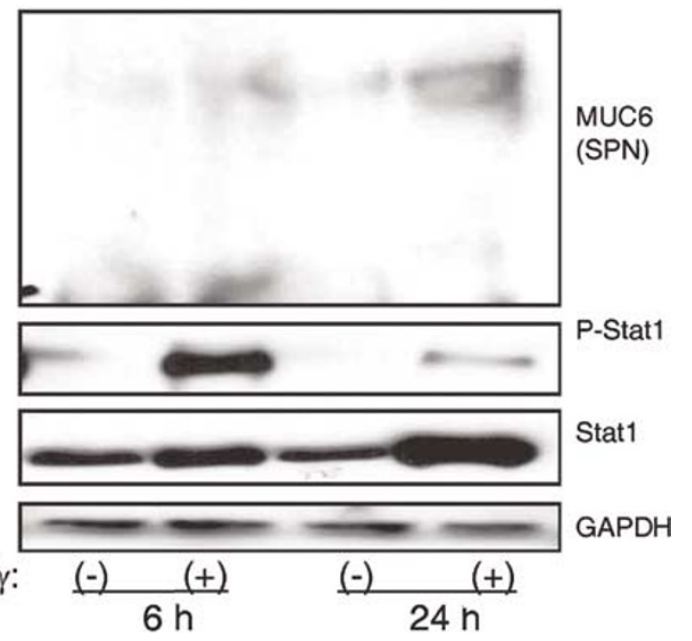

d

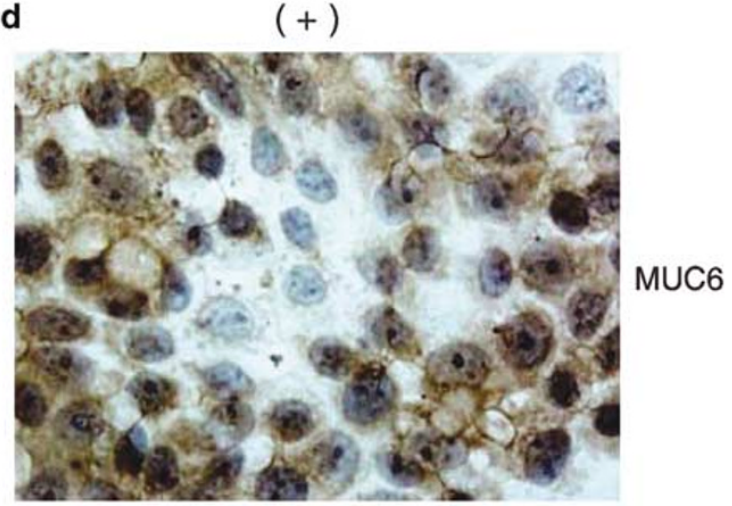

f

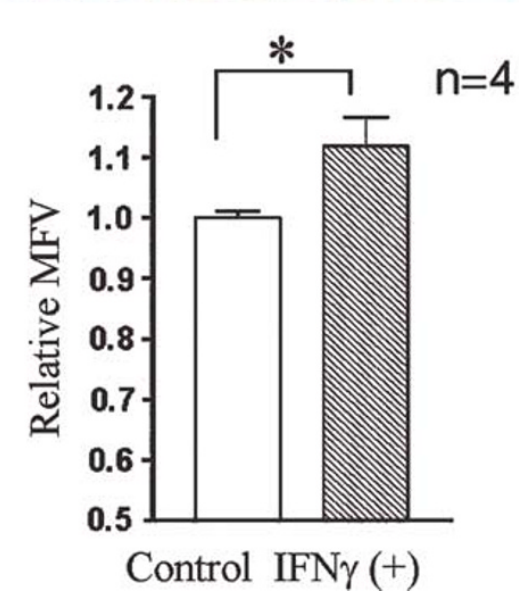

Figure 8 IFN $\gamma$ stimulates MUC6 and TFF2 expression and hypertrophy of NCI-N87 cells. (a) RT-PCR analysis of mRNA expression for MUC6, TFF2, pepsinogen I (PGA), pepsinogen II (PGC), intrinsic factor and HK-ATPase with or without IFN $\gamma$ (10 U/ml) treatment. (b) Western blot analysis of protein extracts from cells with or without IFN $\gamma$, using antibodies against MUC6, STAT1, phospo-STAT1and

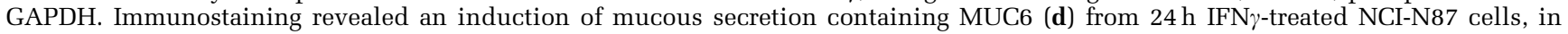
comparison to the vehicle-treated cells (c). This was accompanied by an increase in the cell size, represented by an increase in the mean forward scatter value (MFV) (e) using flow cytometry, and quantified to be $11.6 \pm 3.2\left({ }^{*} P<0.05\right)(\mathbf{f})$.

also been reported for INS-GAS, ${ }^{34}$ DMP777-treated ${ }^{10}$ and H. felis-infected ${ }^{8}$ mice. Noticeably, hypergastrinemia and oxyntic atrophy are characteristic of all three of these mouse models. By contrast, we show here that the expanded mucous neck cell population in $\mathrm{G}-/$ - mice is more centrally located. The loss of chief cells was much less remarkable in $\mathrm{G}-$ / - mice, even at 12 months of age (data not shown). Comparison of these four mouse models therefore suggests a possible connection between gastrin levels and chief cell-differentiation, since hypergastrinemia is accompanied by a more dramatic loss of 
chief cells, whereas, the chief cells were better preserved in the gastrin-deficient mice.

IFN $\gamma$ is the most predominant Th1 cytokine produced in Helicobacter-infected stomachs. ${ }^{35,36}$ In the present study, we showed that IFN $\gamma$ is one of the primary cytokines in the inflamed gastric mucosa of $\mathrm{G}-/$ - mice, and that IFN $\gamma$ infusion was sufficient to stimulate the emergence of the mucosal phenotype observed in the G-/- mice. These results suggest that a Th1-predominant gastritis and subsequent mucosal responses may not be specific for $H$. pylori, but may be induced by other bacteria capable of infecting the mouse stomach. ${ }^{5}$ IFN $\gamma$ is known to play a pivotal role in both protection and tissue-damaging gastritis. ${ }^{37,38}$ Apart from its effects on mucosal immunity, IFN $\gamma$ has been suggested to stimulate gastric epithelial cell apoptosis, by promoting the production of nitric oxide (NO), ${ }^{39}$ or by enhancing the attachment of bacteria to the gastric epithelia. ${ }^{40}$ Identification of the lineage specific markers, not only provided us with clues regarding the origin of the mucous cells even after they change morphology in pathological conditions, but also allowed us to study this mucosal response at the molecular level. By demonstrating IFN $\gamma$ induction of mucous neck cell-specific genes, such as mucus components MUC6 and TFF2, we raised the potential for this proinflammatory cytokine to elicit a protective function, which can help eliminate the invading bacteria and minimize mucosal cell injury. Indeed, a recent microarray study supports our observation, by showing that IFN $\gamma$-regulated mucous cell specific genes are induced following $H$. pylori infection. ${ }^{41}$

Mucous neck cells whose major known physiological function is to secrete mucus are situated in a critical location juxtaposed between the acid and enzyme-secreting cells. ${ }^{30}$ It is now known that in addition to the barrier-type protective properties of mucus, mucus also contains biologically active molecules including mucins, ${ }^{28} \mathrm{TFF}^{26,27}$ and the epidermal (EGF) growth factor family members. ${ }^{30}$ Mucus transports the zymogenic contents of chief cells and acid away from parietal cells into the gastric lumen, while simultaneously providing an effective layer of protection to the surrounding cell layer. Our previous study showed that maximizing acid secretion may be a common response of the gastric mucosa to bacterial colonization. ${ }^{5}$ Perhaps not surprising, there is also an increase in the production of mucus, in order to enhance cell protection against potential injury from bacteria or from the host immune response. TFF2/SP-deficient mice confirmed an important role for this trefoil peptide in promoting mucosal healing, through the stimulation of proliferation and downregulation of gastric acid secretion. ${ }^{42}$ Furthermore, $O$-glycans linked to mucin glycoproteins, for example, MUC6, have recently been shown to function as a natural antibiotic, capable of protecting the host from $H$. pylori infection. ${ }^{43}$ As demonstrated here, the expansion of the mucous neck cell compartment under pathological conditions, for example, proinflammatory cytokines, initially represents an increase in mucus production reflecting an enlargement of individual cells filled with secretory granules. Furthermore there are more mucous neck cells perhaps due to an increasing number of proliferating stem/progenitor cells that favor commitment to the neck cell lineage at the price of parietal/chief cells. Subsequently, imbalanced mucosal cell proliferation may in turn serve as a factor promoting gastric transformation.

\section{Acknowledgements}

This work was supported by the Public Health Service Grants R01 DK61410 to JLM, and the Cell Biology Core of P01DK62401 to JLM. We express our appreciation to Drs Yana Zavros and Longchuan Bai, and Ms Judy Poore of the Cell Biology Michigan DDRC Center (P30DK34933), for invaluable technical assistance. We also thank Kathy McClinchey (McClinchey Histology Lab, Inc., Stockbridge, MI, USA) for paraffin embedding and sectioning fixed tissues.

\section{References}

1 Correa P. Helicobacter pylori and gastric cancer: state of the art. Cancer Epidemiol Biomarkers Prev 1996;5: 477-481.

2 Correa P. Is gastric cancer preventable? Gut 2004;53: 1217-1219.

3 Peek Jr RM, Blaser MJ. Helicobacter pylori and gastrointestinal tract adenocarcinomas. Nat Rev Cancer 2002;2:28-37.

4 Correa P, Shiao YH. Phenotypic and genotypic events in gastric carcinogenesis. Cancer Res 1994;54: 1941s-1943s.

5 Zavros Y, Rieder G, Ferguson A, et al. Genetic or chemical hypochlorhydria is associated with inflammation that modulates parietal and G-cell populations in mice. Gastroenterology 2002;122:119-133.

6 Zavros Y, Kang W, Rathinavelu S, et al. Chronic gastritis in the hypochlorhydric gastrin-deficient mouse progress to adenocarcinoma. Oncogene 2005, in press.

7 Schmidt PH, Lee JR, Joshi V, et al. Identification of a metaplastic cell lineage associated with human gastric adenocarcinoma. Lab Invest 1999;79:639-646.

8 Wang TC, Goldenring JR, Dangler C, et al. Mice lacking secretory phospholipase A2 show altered apoptosis and differentiation with Helicobacter felis infection. Gastroenterology 1998;114:675-689.

9 Nomura S, Baxter T, Yamaguchi H, et al. Spasmolytic polypeptide expressing metaplasia to preneoplasia in H. felis-infected mice. Gastroenterology 2004;127: 582-594.

10 Goldenring JR, Ray GS, Coffey RJ, et al. Reversible drug-induced oxyntic atrophy in rats. Gastroenterology 2000;118:1080-1093.

11 Yamaguchi $\mathrm{H}$, Goldenring JR, Kaminishi $\mathrm{M}$, et al. Association of spasmolytic polypeptide-expressing 
metaplasia with carcinogen administration and oxyntic atrophy in rats. Lab Invest 2002;82:1045-1052.

12 Elso CM, Lu X, Culiat CT, et al. Heightened susceptibility to chronic gastritis, hyperplasia and metaplasia in Kcnq1 mutant mice. Hum Mol Genet 2004;13: 2813-2821.

13 Judd LM, Alderman BM, Howlett M, et al. Gastric cancer development in mice lacking the SHP2 binding site on the IL-6 family co-receptor gp130. Gastroenterology 2004;126:196-207.

14 Halldorsdottir AM, Sigurdardottrir M, Jonasson JG, et al. Spasmolytic polypeptide-expressing metaplasia (SPEM) associated with gastric cancer in Iceland. Dig Dis Sci 2003;48:431-441.

15 Emanuel R. Pathology, 3rd edn. Lippincott-Raven: Philadelphia, 1999.

16 Friis-Hansen L, Sundler F, Li Y, et al. Impaired gastric acid secretion in gastrin-deficient mice. Am J Physiol 1998;274:G561-G568.

17 Lyer PN, Wilkinson KD, Goldstein LJ. An - $N$-acetyl-Dglycosamine binding lectin from Bandeiraea simplicifolia seeds. Arch Biochem Biophys 1976;177:330-333.

18 Ebisu S, Goldstein IJ. Bandeiraea simplicifolia lectin II. Methods Enzymol 1978;50:350-354.

19 Livak KJ, Schmittgen TD. Analysis of relative gene expression data using real-time quantitative PCR and the 2(-delta delta C(T)) method. Methods 2001;25: 402-408.

20 Silberg DG, Sullivan J, Kang E, et al. Cdx2 ectopic expression induces gastric intestinal metaplasia in transgenic mice. Gastroenterology 2002;122:689-696.

21 Yuasa Y. Control of gut differentiation and intestinaltype gastric carcinogenesis. Nat Rev Cancer 2003;3: 592-600.

22 Mutoh H, Sakurai S, Satoh K, et al. Development of gastric carcinoma from intestinal metaplasia in Cdx2transgenic mice. Cancer Res 2004;64:7740-7747.

23 Basque JR, Chenard M, Chailler P, et al. Gastric cancer cell lines as models to study human digestive functions. J Cell Biochem 2001;81:241-251.

24 Taupin D, Wu DC, Jeon WK, et al. The trefoil gene family are coordinately expressed immediate-early genes: EGF receptor- and MAP kinase-dependent interregulation. J Clin Invest 1999;103:R31-R38.

25 Bulitta CJ, Fleming JV, Raychowdhury R, et al. Autoinduction of the trefoil factor 2 (TFF2) promoter requires an upstream cis-acting element. Biochem Biophys Res Commun 2002;293:366-374.

26 Lefebvre $\mathrm{O}$, Wolf $\mathrm{C}$, Kedinger $\mathrm{M}$, et al. The mouse one P-domain (pS2) and two P-domain (mSP) genes exhibit distinct patterns of expression. J Cell Biol 1993;122: 191-198.

27 Jeffrey GP, Oates PS, Wang TC, et al. Spasmolytic polypeptide: a trefoil peptide secreted by rat gastric mucous cells. Gastroenterology 1994;106:336-345.

28 Ho SB, Roberton AM, Shekels LL, et al. Expression cloning of gastric mucin complementary DNA and localization of mucin gene expression. Gastroenterology 1995;109:735-747.

29 Suzaki E, Kataoka K. Lectin cytochemistry in the gastrointestinal tract with special reference to glyco- sylation in the Golgi apparatus of Brunner's gland cells. J Histochem Cytochem 1992;40:379-385.

30 Hanby AM, Poulsom R, Playford RJ, et al. The mucous neck cell in the human gastric corpus: a distinctive, functional cell lineage. J Pathol 1999;187: 331-337.

31 Suzuki S, Tsuyama S, Murata F. Cells intermediate between mucous neck cells and chief cells in rat stomach. Cell Tissue Res 1983;233:475-484.

32 Karam SM, Leblond CP. Dynamics of epithelial cells in the corpus of the mouse stomach. III. Inward migration of neck cells followed by progressive transformation into zymogenic cells. Anat Rec 1993;236:297-313.

33 Fujita K, Kaneko K. Immunohistochemical examination of the relationship between two types of mucous neck cell and the intermediate cells in the rat fundic gland. Okajimas Folia Anat Jpn 1994;71: 137-142.

34 Wang TC, Dangler CA, Chen D, et al. Synergistic interaction between hypergastrinemia and Helicobacter infection in a mouse model of gastric cancer. Gastroenterology 2000;118:36-47.

35 Karttunen R, Karttunen T, Ekre HP, et al. Interferon gamma and interleukin 4 secreting cells in the gastric antrum in Helicobacter pylori positive and negative gastritis. Gut 1995;36:341-345.

36 Mohammadi M, Czinn S, Redline R, et al. Helicobacter-specific cell-mediated immune responses display a predominant Th1 phenotype and promote a delayedtype hypersensitivity response in the stomachs of mice. J Immunol 1996;156:4729-4738.

37 Akhiani AA, Pappo J, Kabok Z, et al. Protection against Helicobacter pylori infection following immunization is IL-12-dependent and mediated by Th1 cells. J Immunol 2002;169:6977-6984.

38 Eaton KA, Mefford M, Thevenot T. The role of T cell subsets and cytokines in the pathogenesis of Helicobacter pylori gastritis in mice. J Immunol 2001;166: 7456-7461.

39 Jung ID, Yang SY, Park CG, et al. 5-Fluorouracil inhibits nitric oxide production through the inactivation of IkappaB kinase in stomach cancer cells. Biochem Pharmacol 2002;64:1439-1445.

40 Fan X, Crowe SE, Behar S, et al. The effect of class II major histocompatibility complex expression on adherence of Helicobacter pylori and induction of apoptosis in gastric epithelial cells: a mechanism for T helper cell type 1-mediated damage. J Exp Med 1998; 187:1659-1669.

41 Mueller A, Merrell DS, Grimm J, et al. Profiling of microdissected gastric epithelial cells reveals a cell type-specific response to Helicobacter pylori infection. Gastroenterology 2004;127:1446-1462.

42 Farrell JJ, Taupin D, Koh TJ, et al. TFF2/SP-deficient mice show decreased gastric proliferation, increased acid secretion, and increased susceptibility to NSAID injury. J Clin Invest 2002;109:193-204.

43 Kawakubo M, Ito Y, Okimura Y, et al. Natural antibiotic function of a human gastric mucin against Helicobacter pylori infection. Science 2004;305:10031006. 